\title{
Study on Development and Characterization of Banana-Bamboo Fibers Hybrid Composite
}

\author{
Ramesh $^{1}$, Shridhar ${ }^{2}$, Arvind Kumar ${ }^{3}$, Maruthi Prashanth ${ }^{4}$ \\ Research Scholar, Mechanical Engineering Department, NITK Suratkal, Karnataka, India ${ }^{1}$ \\ Assistant Professor, Mechanical Engineering Department, BIT, Mangalore, Karnataka, India ${ }^{2,3,4}$
}

\begin{abstract}
Natural fiber has emerged as a renewable and economical substitute to synthetic materials such as glass, carbon, which are used as reinforcements. In this paper work, the objective was to develop, investigate and analyze the mechanical properties of a composite material using bamboo fiber and banana fiber polymer. The long bamboo fiber was extracted using chemical digestion and maceration methods. The fabrication of the composite was carried out using epoxy resin as the matrix and the bamboo fiber and the banana fiber as reinforcement. Tests were carried out to determine the mechanical properties such as tensile, hardness and bending strengths. The results were studied and compared with the conventional materials and it process that the material developed can be used in structural applications with strong dependence on its mechanical properties.
\end{abstract}

Keywords: Reinforcement, epoxy resin, matrix, bamboo fiber, chemical digestion, banana fiber.

\section{INTRODUCTION}

The demand placed on materials for better overall performance is so great and diverse that no one material can satisfy them. This limitation has led to a resurgence of the ancient concept of combining different materials in an integratecomposite materials to satisfy the user requirement, this composite material system result in a performance that cannot be attained by individual constituent which offer a great advantage of a flexible design. Natural fibers are now regarded as alternative to glass fiber for use as reinforcements in composite materials. Their advantages include low cost, low density, high strength-to-weight ratio, and resistance to breakage during processing, low energy content and recyclability. The properties of natural fiber-based composites can be affected or modified by a number of factors such as fiber combinations, processing method, fiber volume fraction, aspect ratio, water absorption, etc. The process parameters and their influence on the final properties vary with different fiber-matrix combinations. The fabrication method has a significant impact on the resulting properties. Various processing methods, e.g. compression moulding, injection moulding, extrusion moulding, and hand lay-up, are available for natural fiber composite materials. Injection moulding improves the fiber dispersion, hence increasing the tensile and properties of natural fibers.

\section{LITERATURE REVIEW}

In recent years, the interest of scientists and engineers has turned over on utilizing plant fibers as effectively and economically as possible to produce good quality fiber-reinforced polymer composites for structural, building, and other needs.

[1] B. D. Agarwal and L. J. Broutman compared the mechanical properties of banana fiber reinforced polyester with jute, sisal and coir reinforced composites. Water absorption showed an increase in water uptake with increase in fiber content. Maximum tensile strength was observed at $30 \mathrm{~mm}$ fiber length while maximum impact strength was observed for $40 \mathrm{~mm}$ fiber length. Comparative analysis with other natural fibers shows banana fiber composite has superior mechanical properties than other composites.

[2] S. Joseph, M. S. Sreekalab, Z. Oommena, P. Koshyc and S.Thomas investigated the effect of alkali treatment on the banana fiber and its polyurethane reinforced composite. The study included the treatment of banana fibers with 10 $\%$ wt of $\mathrm{NaOH}$, prediction of critical fiber length, tensile strength of the fiber and composite. The study shows that alkali treatment improves the interfacial adhesion between fiber and matrix which in turn increases the tensile strength of the composite.

[3] M. Ahmed, and F. A Kamke investigated the influence of silica powder on tensile properties of banana fiber/epoxy composite. It showed that the addition of silica increases the modulus of elasticity and impact strength of composite. It has observed that tensile strength of bamboo-fiber reinforced plastic (BFRP) composite is comparatively equivalent to that of the mild steel, whereas their density is only $12 \%$ of that of the mild steel. Hence, the BFRP composites can be extremely useful in structural applications. 


\section{FABRICATION PROCESS}

a) HAND LAYUP PROCESS:

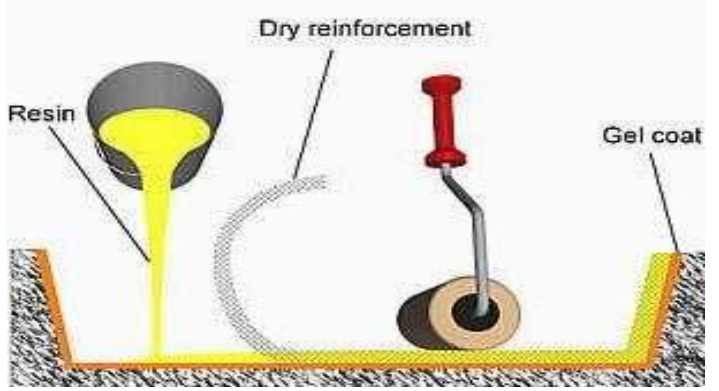

Fig. No 3.1: Hand layup process

Hand lay-up is the open molding method of the composite fabrication processes. Glass or other reinforcing materials or woven fabric or roving is positioned manually in the open mold, and resin is poured, brushed, or sprayed over and into the glass plies. Entrapped air is removed manually with squeegees or rollers to complete the laminates structure. Room temperature curing polyesters and epoxies are the most commonly used matrix resins. Curing is initiated by a catalyst in the resin system, which hardens the fiber reinforced resin composite without external heat. For a high quality part surface, a pigmented gel coat is first applied to the mold surface.

First of all, a release gel is sprayed on the mold surface to avoid the sticking of polymer to the surface. Thin plastic sheets are used at the top and bottom of the mold plate to get good surface finish of the product. Reinforcement in the form of woven mats or chopped strand mats are cut as per the mold size and placed at the surface of mold after perspex sheet. Then thermosetting polymer in liquid form is mixed thoroughly in suitable proportion with a prescribed hardner (curing agent) and poured onto the surface of mat already placed in the mold. The polymer is uniformly spread with the help of brush. Second layer of mat is then placed on the polymer surface and a roller is moved with a mild pressure on the mat-polymer layer to remove any air trapped as well as the excess polymer present. The process is repeated for each layer of polymer and mat, till the required layers are stacked. After placing the plastic sheet, release gel is sprayed on the inner surface of the top mold plate which is then kept on the stacked layers and the pressure is applied. After curing either at room temperature or at some specific temperature, mold is opened and the developed composite part is taken out and further processed. The schematic of hand lay-up is shown in figure 1. The time of curing depends on type of polymer used for composite processing.

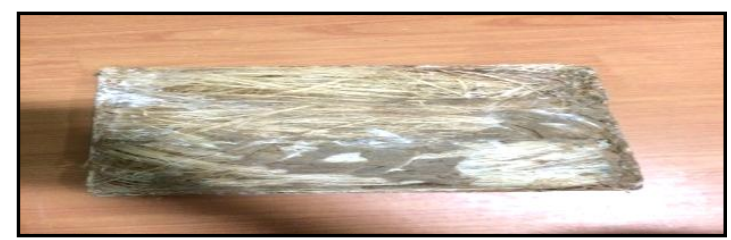

Fig. No 3.2: Before fabrication

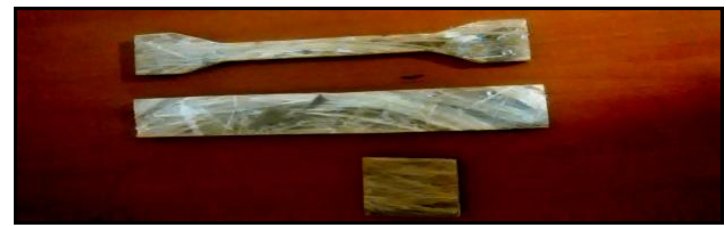

Fig. No 3.3: Work piece after fabrication.

\section{MATERIAL DESCRIPTION}
a) BAMBOO FIBER
b) BANANA FIBER
c) EPOXY RESIN

\section{a) BAMBOO FIBER:}

Bamboo fiber is a cellulose fiber extracted or fabricated from natural bamboo, and possibly other additives, and is made from the pulp of bamboo plants. It is usually not made from the fibers of the plant, but is a synthetic viscose made from bamboo cellulose. 


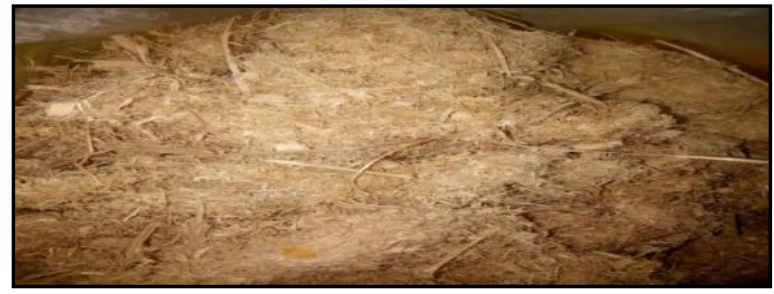

Fig. No 4.1: Bamboo fiber

b) BANANA FIBER:

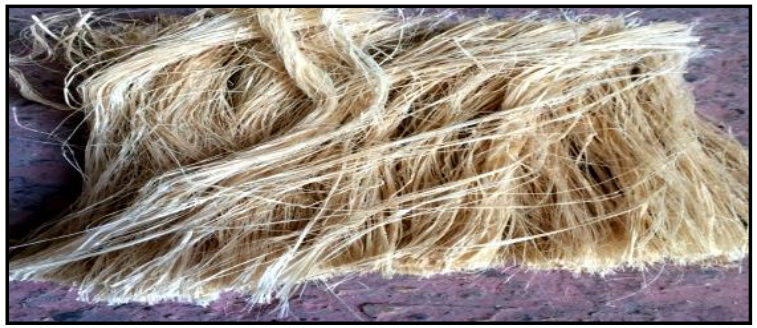

Fig. No 4.2: Banana fiber

Banana fiber is obtained from the pseudostem of the banana plant by decortication i.e. stem is generally scrapped with the help of a blunt knife. Banana plant cannot be grown except under tropical conditions, as it bears numerous leaves and only very short roots, it requires humidity both in the atmosphere and in the soil, and is only able to thrive in areas which have rainfall more or less evenly distributed throughout the year. A bunch of fibers are mounted or clamped on a stick to facilitate segregation.

\section{c) EPOXY RESIN:}

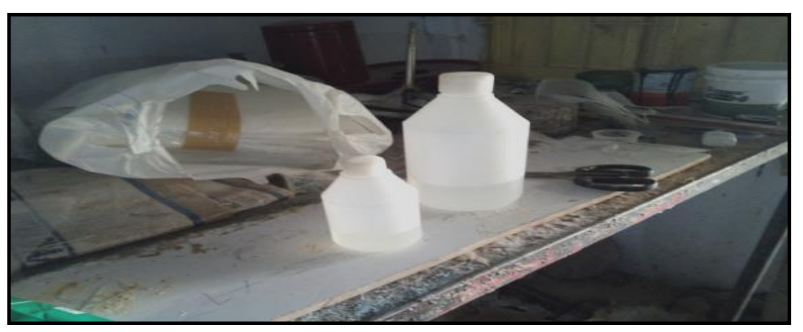

Fig. No 4.3: Epoxy resin

Epoxy resins, also known as polyepoxides, are a class of reactive prepolymers and polymers which contain epoxide groups. Epoxy resins may be reacted (cross-linked) either with themselves through catalytic homopolymerisation, or with a wide range of co-reactants including polyfunctional amines, acids (and acid anhydrides), phenols, alcohols and thiols. These co-reactants are often referred to as hardeners or curatives, and the cross-linking reaction is commonly referred to as curing. Reaction of polyepoxides with themselves or with polyfunctional hardeners forms a thermosetting polymer, often with high mechanical properties, temperature and chemical resistance.

\section{Typical properties of materials:}

Table 5.1 Typical properties of materials

\begin{tabular}{|l|l|l|}
\hline PROPERTY & BANANA & EPOXY \\
\hline Density $\left(\mathrm{Kg} / \mathrm{m}^{3}\right)$ & 1350 & 1200 \\
\hline Young's modulus $(\mathrm{Gp})$ & 3.48 & 1.359 \\
\hline Poisson's Ratio & 0.28 & 0.3 \\
\hline
\end{tabular}

\section{Materials and methods:}

This describes the details of processing of the composites and the experimental procedures carried out for their characterization and tests which the composite specimens are subjected to the raw materials used in this work are: Selection of fiber are Banana fibers, Jute Fiber and, Resin Epoxy (LY-556) and hardener (HY-917). 


\section{Fabrication of Composites:}

The fabrications of composite slab are carried out by conventional hand layup technique. The dimensions of length and breadth is of $300 * 300 \mathrm{~mm}$ was used to prepare the specimen. The composite specimen consists of totally 3 Layers of Banana Fiber for the preparation of one sample. A measured amount of epoxy is taken and mixed with the hardener in the ratio of 10:1 the layers of fibers were fabricated by adding the required amount of epoxy resin. The Banana fiber is mounted on the table and then epoxy resin applies and next layer is jute fiber. Before the resin gets dried, the second layer of natural fiber is mounted over the Banana fiber. The process is repeated till 3 layers of fiber. The epoxy resin applied is distributed to the entire surface by means of a roller. The air gaps formed between the layers during the processing were gently squeezed out. The processed wet composite were then pressed hard and the excess resin is removed and dried. Finally these specimens were hydraulic pressed to force the air present in between the fibers and resin, and then kept for several hours to get the perfect samples. After the composite material dried completely, the composite material was taken out from the hydraulic press and rough edges were neatly cut and removed as per the required ASTM standards.

\section{EXPERIMENTATION}

Types of tests conducted:

1 Tensile test

2 Bending test

3 Hardness test

1) TENSILE TEST:

Tensile specimens are machined from the material to be tested in the desired orientation and according to the standards.

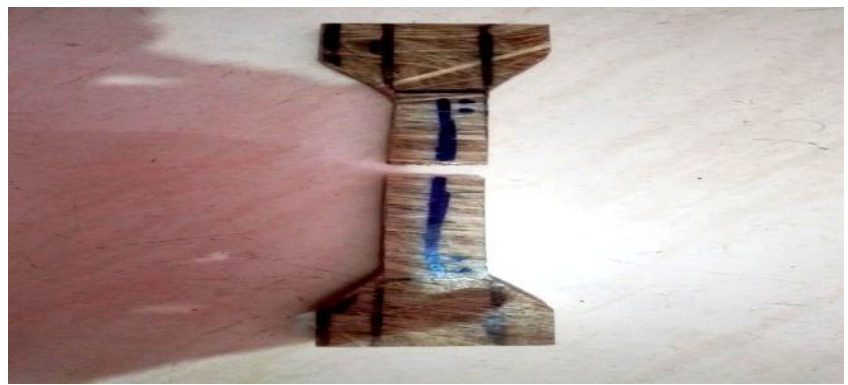

Fig. No 5.2 : Work piece after tensile test

Tensile Test:

Sample

Specimen width

: Banana \&Bamboo Epoxy

Specimen thickness

Yield stress

Tensile stress

: $8.72 \mathrm{~mm}$

Percentage elongation

: $4.071 \mathrm{~N} / \mathrm{mm}^{2}$

: $5.157 \mathrm{~N} / \mathrm{mm}^{2}$

: $0.72 \%$

\section{Stress V/S Strain graph for tensile test:}

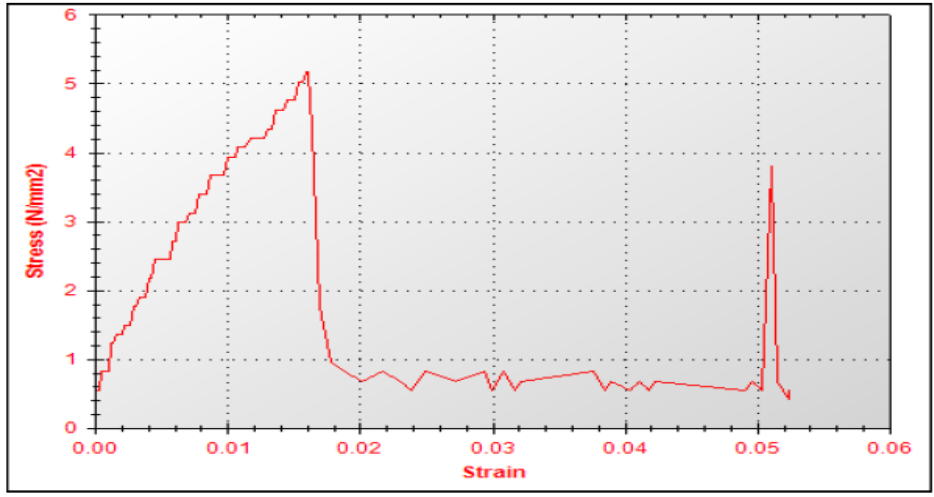

Graph 5.1: Stress v/s strain graph for tensile test 


\section{2) BENDING TEST:}

The three points bending flexural test provides values for the modulus of elasticity in bending, flexural stress, flexural strain and the flexural stress-strain response of the material.

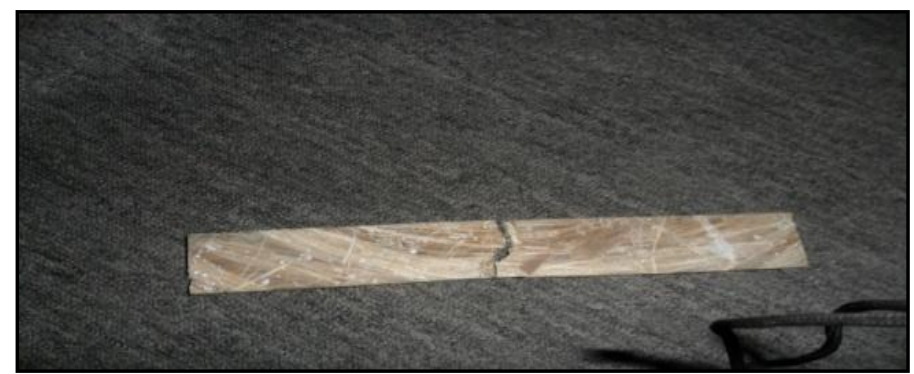

Fig. No 5.4: Work piece after bending test

\section{Bending Test:}

$\begin{array}{ll}\text { Sample } & \text { : Banana \& Bamboo Epoxy } \\ \text { Width } & : 39.52 \mathrm{~mm} \\ \text { Thickness } & : 8.32 \mathrm{~mm} \\ \text { Bend strength } & : 2.190 \mathrm{~N} / \mathrm{mm}^{2}\end{array}$

Stress V/S Strain graph for bending test:

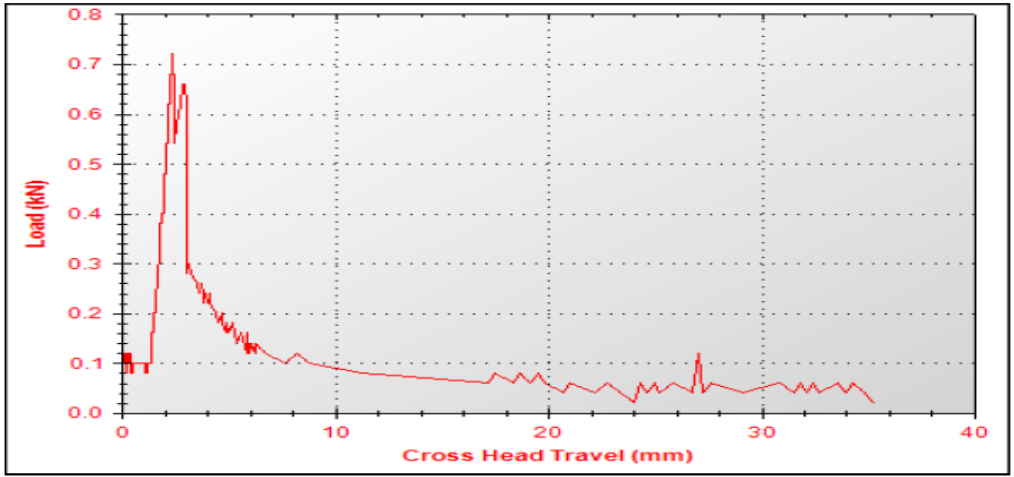

Graph 5.2: Stress v/s strain graph for bending test

\section{3) SHORE HARDNESS TEST:}

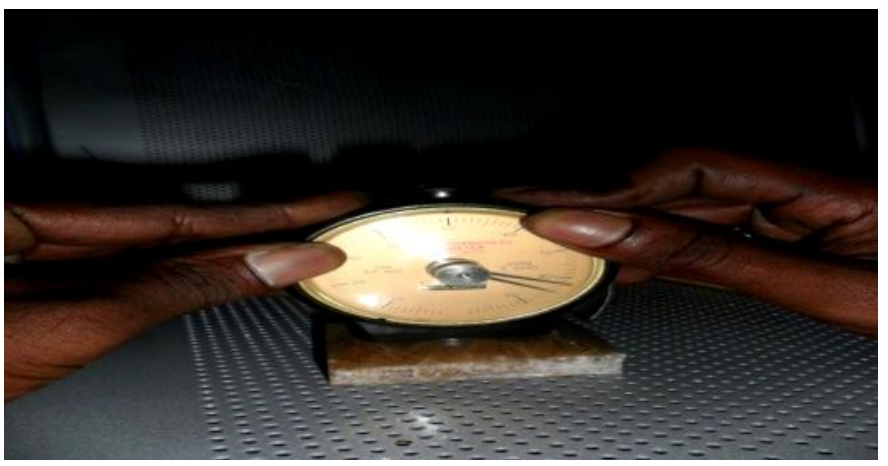

Fig. No 5.5: Shore hardness Test

Shore Hardness, using either the Shore A or Shore D scale, is the preferred method for rubbers/Elastomers and is also commonly used for 'softer' plastics such as polyolefins, fluoropolymers, andvinyls.

\section{SHORE D HARDNESS TEST:}

Sample : Banana \& Bamboo Fiber + Epoxy Resin

Ambient temperature $\quad: 25^{\circ} \mathrm{C}$ 
ISO 3297:2007 Certified

Vol. 4, Issue 4, April 2017

Table 5.1 Observed value of shore hardness test

\begin{tabular}{|l|l|l|l|l|l|}
\hline Sl. no. & Sample & \multicolumn{3}{|c|}{$\begin{array}{c}\text { Observed values, shore d } \\
\text { hardness number }\end{array}$} & $\begin{array}{c}\text { Average, shore d } \\
\text { hardness number }\end{array}$ \\
\hline & & 1 & 2 & 3 & \\
\hline 1 & Banana \& Bamboo Fiber + Epoxy Resin & 84 & 83 & 84 & 84 \\
\hline
\end{tabular}

\section{CONCLUSION}

The tensile and flexural properties of epoxy composites reinforced with bamboo fiber and banana fiber have been studied and discussed. It has been noticed that the mechanical properties of the composites such as tensile strength and bend strength of the composites are also greatly influenced by the fiber fraction and type. This work shows that successful fabrication of bamboo fiber and banana fiber reinforced epoxy composites is possible by simple hand lay-up technique. The developed long bamboo fiber reinforced composite (LBFRC) can be used in different engineering applications based on the available data provided by this research report.

\section{REFERENCES}

[1] B. D. Agarwal and L. J. Broutman. “Analysis and performance of fiber Composites” 3rd ed. New York: John Wiley \& Sons pp.3 -12.

[2] S. Joseph, M. S. Sreekalab, Z. Oommena, P. Koshyc and S.Thomas "A comparison of the mechanical properties of phenol formaldehyde composites reinforced with banana fibres and glass fibres", Compos. Sci. Technol. 62(1): 1857-1868, 2002.

[3] M. Ahmed, and F. A Kamke, "Analysis of bamboo for structural composite materials: physical and mechanical properties", wood science Technology, 39(6): 448-459, 2006.

[4] S. Biswas, A. Satapathy, and A. Patnaik , "Effect of Ceramic Fillers on Mechanical Properties of Bamboo fiber Reinforced Epoxy Composites": A Comparative Study, Advanced Materials Research,1031-1034,2010.

[5] J. Holbery and D. Houston "Natural-Fiber-Reinforced Polymer Composites in Automotive Applications", JOM, 58(11): 80-6, 2006.

[6] D. Nabi Sahieb, J.P. Jog, 1999, "Natural fiber polymer composites, a review”, Advances in Polymer Technology, Vol. 18, No. 4, pp.351-363. 